\title{
Representações sociais de acadêmicos de psicologia acerca da loucura
}

Representaciones sociales de académicos de psicología acerca de la locura

Social representations of psychology students about madness

Adriano Schlosser

Universidade Federal de Santa Catarina - Florianópolis - Brasil

Gabriel Fernandes Camargo Rosa

Centro Universitário de Brusque - Brusque - Brasil

\section{RESUMO}

Dentre os diversos fenômenos, a loucura tem sido destaque no campo das Representações Sociais tendo diversas formas de compreensão ao longo da história. Este trabalho teve como objetivo analisar as representações sociais de acadêmicos de Psicologia acerca da loucura. Participaram da pesquisa 50 acadêmicos de uma instituição de Ensino Superior, sendo 25 participantes pertencentes ao grupo de iniciantes do curso e 25 do grupo de concluintes, visando a comparação entre os dados levantados. Utilizou-se a técnica de grupo focal como instrumento de investigação para a coleta de dados. As falas foram transcritas e organizadas de acordo com categorias posteriormente estabelecidas, tendo como método para a interpretação dos dados a técnica da análise do discurso. Constatou-se noções diversas acerca do que é propriamente loucura, sendo os meios de comunicação o principal veiculador de representações por parte dos acadêmicos ingressantes, enquanto os concluintes embasam suas percepções em dois pólos teóricos distintos: o campo psicopatológico e o campo social.

Palavras-chaves: Loucura. Representação social. Psicologia.

\section{RESUMEN}

Entre los diversos fenómenos, la locura ha sido destacado en el campo de las representaciones sociales, con diversas formas de comprensión de la historia. El objetivo de este estudio fue analizar las representaciones sociales de los estudiantes de psicología sobre la locura. Los participantes fueron 50 estudiantes de una institución de educación superior, veinte y cinco de los principiantes del curso y veinte y cinco estudiantes concluyentes, con el fin de comparar los datos recogidos. Se utilizó la técnica de grupo focal como una herramienta de investigación para la recopilación de datos. Las líneas fueron transcritas y organizados de acuerdo a las categorías establecidas posteriormente, con el método para la interpretación de datos de la técnica de análisis de voz. Se encontraron diversas 
nociones de lo que es la locura adecuada, los medios de comunicación es el principal difusor de las representaciones por el primer año académico, mientras que los graduados apuntalan sus percepciones en dos polos teóricos diferentes: psicopatología y el campo social.

Palabras clave: Locura. Representación social. Psicología.

\begin{abstract}
Among the several studies in Social Representation, the madness has been highlighted, having several forms of understanding throughout history. This article analyze the social representations of psychology students about madness. Fifty students from an institution of Higher Education participated in the study, being twenty of five participants from the group of beginners of the course and twenty of five from the group of conclusion, for comparative purposes between the data raised. The focal group technique was used as a research tool for data collection. The speeches were transcribed and organized according to categories established later, using as a method for the interpretation of data the technique of discourse analysis. Various notions about what is really madness have been observed, with the media being the main vehicle for representations by the incoming academics, while the students base their perceptions on two distinct theoretical poles, being the psychopathological field and the social field.
\end{abstract}

Keywords: Madness. Social representation. Psychology.

\section{Introdução}

Tem-se percebido o crescimento do número de filmes, novelas e seriados televisivos que abordam temáticas referentes a manifestações de sofrimento psíquico, propiciando maior contato da população com este tipo de fenômeno. A opção por pesquisar o fenômeno da loucura sob a óptica de acadêmicos de Psicologia parte do pressuposto de que estes, antes de entrarem para a graduação, são influenciados diretamente pelos meios de comunicação, o que repercute em seus sistemas de crenças e valores sobre o fenômeno da loucura. Assim, diversas mensagens apresentadas em tais meios acabam por enfatizar práticas sociais, podendo levá-los a escolher fazer tal curso devido à preferência por tais temáticas.

Compreendendo a noção de que a teoria das representações sociais (TRS) concebe o papel da mídia como importante produtor de significados e ideologias, o presente estudo foca-se na temática da loucura, usando como arcabouço teórico a TRS. Moscovici (1978) define-a como sendo um conjunto de afirmações, conceitos e explicações que formam uma teoria do senso comum, inserida no universo das opiniões e conceitos dados aos fenômenos do cotidiano. Jodelet (2001) complementa tal construto ao enfatizar que as representações sociais são uma forma de conhecimento elaborado e partilhado socialmente, com um objetivo prático, convergindo para a construção de uma realidade comum a um grupo social sobre um determinado objeto. A partir destas representações, pode-se acessar a maneira como indivíduos compreendem determinado fenômeno e quais atitudes tomam frente ao mesmo (Rouquette, 1998).

Dentro da psicologia social, as representações sociais refletem a forma como indivíduo e sociedade interage na construção da realidade, passando pelo processo de comunicação (Arruda, 2002). Nesta perspectiva, a TRS operacionaliza um modelo de compreender e analisar o pensamento social em sua dinâmica e diversidade. Desta forma, as representações sociais despontam como uma das possibilidades de estudo sobre o senso comum, assim como outros construtos, como: atitudes, ideologias, imagens sociais, dentre outras (Wachelke \& Camargo, 2007). 
Dois conceitos que integram os estudos sobre RS necessitam ser definidos, uma vez que determinam a própria existência da teoria: universo consensual e universo reificado. Enquanto o universo consensual é formado pelo conhecimento leigo, sendo livremente partilhado por pessoas não especialistas, o universo reificado é composto pelo conhecimento científico e especializado, no qual existe uma hierarquia e um sistema de papéis específicos, dando-se importância à qualidade do saber do indivíduo (Moscovici, 2003). As representações sociais surgem na inter-relação dos universos, no qual o conhecimento científico articula-se aos saberes populares e ao senso comum, dando lugar a uma nova forma de saber, de acordo com a reelaboração do saber por parte dos grupos sociais, bem como dos meios que possuem para tal (Moscovici \& Hewstone, 1986).

As RS, formadas a partir da comunicação, sustentam-se a partir de dois processos sociocognitivos intrinsecamente ligados: objetificação e ancoragem (Moscovici, 1981). São formas específicas em que as RS instituem mediações, materializando uma construção simbólica de um determinado grupo e possibilitando sua concretude em espaços sociais. A objetificação busca sintetizar diversos conteúdos estranhos a uma realidade familiar, ganhando forma de imagens e ideias concretas (Moscovici, 1981). Já a ancoragem é refletida como o processo na qual se classificam as informações sobre um objeto social em relação a estruturas de saberes já existentes, havendo certa coerência entre ao conhecimento novo e aquilo que já existe (Vala, 1996), dependendo assim de uma memória coletiva (Moscovici, 2003).

Dentre os diversos fenômenos estudados, a loucura tem sido destaque neste campo do conhecimento. No que tange a representação social da loucura, a literatura aponta para este fenômeno como sendo fruto de séculos de exclusão e marginalização desta população acometida por sofrimento psíquico (Foucault, 1999; Silva \& Zanello, 2010). Nessa perspectiva, as representações sociais do processo saúde-doença mental podem ser constituídas com base em diversos campos e saberes (tanto científicos quanto culturais), tais como: economia, religião, educação, política, etc. As doenças mentais estiveram e estão presentes nas civilizações e culturas de todos os tempos, sendo que a construção de significados de outrora acerca da loucura juntam-se hoje aos conhecimentos científicos, formando assim uma representação do processo de adoecimento mental (Machado, 2001).

Historicamente, a concepção demonista da era medieval, cuja ideia era de que quem faz coisas estranhas ou diferentes agia em nome do diabo (Pessotti, 1994; Silva \& Zanello, 2010) perdurou até o século XVII, período onde houve o avanço da ciência e de investigações das alterações psíquicas, passando a ser considerada uma doença e não mais uma possessão. O século XIX, também intitulado "o século dos manicômios" (Pessotti, 1986, pg. 9) pelo desenvolvimento da psiquiatria, altos índices de hospitais psiquiátricos e internações,bem como o século $X X$, com a maturidade da medicina psiquiátrica (Pélicier, 1971), deram seguimento à lógica psicopatológica do sofrimento psíquico.

Há poucas décadas, a assistência ao portador de doença mental centrava-se nos hospitais psiquiátricos, que legitimavam as ações sobre a loucura, através da internação e medicalização dos sintomas provenientes dos transtornos apresentados pelo indivíduo, que por sua vez era isolado das interações sociais e familiares. No contexto brasileiro, o modelo substitutivo às práticas manicomiais provém das lutas populares contra o regime militar, inspiradas também nos movimentos europeus e norte-americanos a partir da II Guerra Mundial (Silva, Aciole \& Lancman, 2017). A criação do Sistema Único de Saúde e a Lei n.10.216/2001 (Ministério da Saúde, 2001) que dispõe sobre a proteção e os direitos das pessoas portadoras de transtornos mentais, configuram-se como as principais bases legais do projeto de Reforma Psiquiátrica no país, 
garantindo os direitos de cidadãos aos portadores de transtornos mentais.

$\mathrm{Na}$ prática, os Centros de Atenção Psicossocial (CAPS) vieram substituir o antigo modelo de Núcleos de Atenção Psicosssocial (NAPS), visando possibilitar um serviço de qualidade entre comunidade e internação hospitalar. Atualmente, o modelo de atenção psicossocial em saúde mental prioriza a comunidade onde o usuário reside, visando sua integração social, substituindo assim o modelo de internações (Cunha \& Boarini, 2016), bem como residências terapêuticas, leitos de atenção integral em saúde mental dentro de hospitais gerais, cooperativas de trabalho e geração de renda, dentre outros (Minozzo, Kammzetser, Debastiani, Fait, \& Paulon, 2012).

No que tange a pesquisas referentes ao estudo das representações sociais da loucura e assuntos afins, a obra de Denise Jodelet intitulada Loucuras e Representações sociais (2005), originada de sua tese de doutorado (Jodelet, 1989), é um importante marco teórico sobre o tema. Tal estudo, realizado em uma comunidade rural onde os doentes mentais eram confiados ao cuidado de famílias, sendo estas supervisionadas por um hospital psiquiátrico, trouxe em seu conteúdo algumas informações importantes para a compreensão do fenômeno, tais como: a diferenciação da doença mental das outras doenças, em que os doentes mentais não possuem uma doença, mas "são" a doença (Caldas \& Sá, 2004); práticas de discriminação por parte dos cidadãos para com os pacientes, uma vez que os moradores consideravam-nos como uma ameaça pro serem imprevisíveis e diferentes, o que os marginalizava (Jodelet, 2005).

Não obstante, outros estudos sobre representações sociais e loucura foram desenvolvidos. Em seu estudo sobre representação social da loucura em crianças e em adultos, De Rosa (1987) apontou que as representações do sujeito "louco" apresentamse mais do tipo mágico-fantástica, isto é, núcleos figurativos fundamentado em estereótipos seculares, que associam o louco como "monstruoso" ou "palhaço". Já Krause (2002), ao investigar a representação social sobre problemas psicológicos de uma população chilena de baixo nível socioeconômico, observou a associação da loucura com problemas psicológicos, sendo os elementos representacionais de problemas psicológicos mais próximos da vida cotidiana. Por sua vez, Wagner, Duveen, Themel e Verna (1999) ao investigar a representação social da loucura na cidade hindu de Patna, constatou que nesta região a loucura caracteriza-se de maneira ameaçadora, exigindo tratamento especializado em casos graves, mas que, em casos considerado leves, pode ser tratado no núcleo familiar. Como formas de iniciar o processo de loucura, os entrevistados indicaram as seguintes características: problemas na vida cotidiana, tais como vida sexual reprimida, casamentos infelizes ou violência conjugal, uma vez que há tensão entre as normas sociais proibitivas e os desejos reprimidos.

Os estudos sobre representações sociais da loucura, de uma forma geral, apontam consideravelmente para a questão da alteridade (Wagner et al., 1999) e da diferença (Morant \& Rose, 2002), uma vez que o louco é visto como o outro, alguém imprevisível, perigoso e possivelmente violento. No Brasil, dois trabalhados podem ser considerados como referências sobre tal fenômeno. Alves (1982), ao investigar as representações sociais de doença mental em uma população de favela no Rio de Janeiro, objetivando saber a etiologia da doença mental para os moradores, observou que, para eles, os sintomas patológicos são determinados pelo afastamento das normas que mantém a coesão grupal, incluindo à doença uma dimensão espiritual e considerando o hospital psiquiátrico como último recurso.

Perussi (1995) ao pesquisar a representação social da doença mental entre psiquiatras em Recife-PE verificou duas modalidades de compreensão do fenômeno, sendo elas: saúde/doença $\mathrm{x}$ normal/desvio. 
Por sua vez, Wachelke (2005) propõe que os dois sistemas representacionais que sustentam as representações sociais da loucura (ciência e cultura) não explicam satisfatoriamente este fenômeno enquanto objeto da sociedade, uma vez que mesmo a Ciência repudiando as teorias do senso comum acerca da loucura, aquela não consegue fornecer boas explicações que familiarizem tal fenômeno, permanecendo assim incertezas e obscuridade no assunto, impedindo a ancoragem adequada da loucura, mantendo assim o caráter nãofamiliar e ameaçador.

Morant e Rose (2002), observando as regularidades referentes à representação social da loucura em grande parte dos estudos sobre este tema, apontam que a loucura sugere constituir um desafio para a teoria das representações sociais. Considerando que a doença mental é compreendida e vivenciada como uma ameaça à própria identidade, sendo vista como perigosa e passível de controle e domínio, sua ancoragem seria de caráter provisório e instável. Tendo em vista a premissa de que as RS tornam o não familiar em familiar, e a doença não é vista como algo familiar, este processo não se dá de forma esperada, uma vez que ainda é vista como perigosa pelos indivíduos.

A presente pesquisa teve por objetivo geral analisar as representações sociais de acadêmicos de psicologia acerca da loucura, tanto acadêmicos ingressantes quanto concluintes. Tais dados poderão fornecer uma forma de compreender as opiniões e crenças desta parcela profissional, acarretando em novos dados para o campo científico e profissional.

\section{Método}

Trata-se de um estudo exploratório, de abordagem qualitativa. Também se caracteriza pelas seguintes especificidades: transversal considerando que o mesmo ocorreu num determinado tempo cronológico, descrevendo especificidades dos participantes num determinado momento de sua trajetória de vida (Richardson, 2009) - e de amostragem intencional, uma vez que foram escolhidos de maneira intencional os grupos específicos que compuseram a amostra (Marconi \& Lakatos, 2007).

\section{Participantes}

A pesquisa foi realizada com 50 acadêmicos do curso de Psicologia, divididos em dois grupos diferentes, sendo um formado apenas por estudantes do $1^{\circ}$ período (AC acadêmico calouro) - 25 , no total - e outro por estudantes do $10^{\circ}$ Período (AV - acadêmico veterano) -25 , no total. Os grupos foram compostos por 15 homens e 14 mulheres pelo grupo do $1^{\circ}$ período, e 14 homens e 15 mulheres do grupo do $10^{\circ}$ período, com idade entre 18 e 25 anos $(\mathrm{M}=21$ anos, $D P=2$ anos e 3 meses). O critério para o número de participantes atenta-se para o tipo de análise a qual a pesquisa realizou, sendo utilizada a técnica de fechamento do número amostral por saturação teórica (Fontanella \& Magdaleno Júnior, 2012).

Os períodos acadêmicos escolhidos dizem respeito ao fato de, ainda nos primeiros períodos do curso, os estudantes possivelmente ainda possuem suas representações ancoradas no universo consensual acerca dos transtornos mentais. Já os acadêmicos concluintes, após seu tempo de formação, possivelmente possuem suas representações ancoradas no universo reificado, devido ao embasamento científico proveniente da formação.

\section{Coleta de Dados}

Inicialmente, foi realizado um contato inicial nas salas de aula, com as turmas de Psicologia iniciais e concluintes de uma universidade privada, visando explicar os objetivos da pesquisa e convidar aos interessados à estarem presentes na atividade, com dia e local agendados. Após breve apresentação pessoal dos participantes, foi entregue o Termo de Consentimento Livre e Esclarecido aos participantes, para que os mesmos tivessem as devidas informações sobre a atividade. 
Utilizou-se a técnica de grupo focal como instrumento de investigação da temática para a coleta de dados. Roso (1997) analisa a contribuição que o método de grupo focal viabiliza em pesquisas, sendo que o ponto chave de sua utilização consiste no movimento que permite a produção de dados, mediante a interação grupal que tal técnica possibilita. Por parte do investigador, tal técnica permite maior inclusão deste com o tema a ser trabalhado, principalmente quando as temáticas pesquisadas estão ligadas a componentes ideológicos, subjetivos ou culturais (Vasconcelos, 2002). O tópico para os grupos focais consistiu em uma pergunta, realizada pelos pesquisadores, para possibilitar debates nos grupos sobre o assunto central, visando salientar a temática da loucura, visando tornar o debate o mais aberto possível. A pergunta geradora foi: "Para vocês, o que é loucura?".

Foram realizados dez grupos focais, cinco deles com participação apenas de acadêmicos iniciantes e cinco apenas com acadêmicos concluintes. Cada grupo focal continha a presença de cinco participantes, seguindo as recomendações de Roso (1997) acerca da quantidade de participantes de uma atividade de grupo focal - devendo haver de cinco a sete participantes. O tempo de duração dos grupos foi de uma hora aproximadamente -, onde foram utilizados dois gravadores de áudio, buscando contornar possível falha em algum deles. Ressalta-se que a quantidade de grupos focais realizados levou em consideração o critério de saturação, em que a atividade vai produzindo volume de dados e diversificadas formas de representação, chegando à saturação, onde novos participantes pouco acrescentariam em dados inéditos, trazendo assim confiabilidade à proposta (Bauer \& Aarts, 2008).

\section{Análise de dados}

O método utilizado para a interpretação dos dados foi o de análise do discurso. Seguindo o modelo proposto por Gil (2008), inicialmente foi realizada a transcrição literal de todas as falas dos grupos focais, indicando assim confiabilidade aos dados e minimizando os possíveis vieses por parte dos pesquisadores (Gaskell \& Bauer, 2008). Posteriormente, foi realizada a leitura atenta de todo material, visando olhar o familiar em estranho, por meio do olhar crítico ao material. Na sequência, codificou-se os elementos apresentados nas entrevistas, organizando os temas emergentes, para enfim haver a análise mais profunda, focada nos sentidos apresentados pelos participantes em seus discursos sobre o fenômeno da loucura. Não obstante, ressaltase que a interpretação realizada pelos pesquisadores, embora cuidadosa e criteriosa, não limita novas perspectivas frente ao material.

\section{Considerações Éticas}

No que tange os procedimentos éticos, estes se pautaram no que aponta a resolução ${ }^{\circ}$ 196/1996 do Conselho Nacional de Saúde (CNS), que regula sobre os cuidados éticos em pesquisas envolvendo Seres Humanos, assim como também se baliza no que pondera o Conselho Federal de Psicologia (CFP), em sua resolução $n^{\circ}$ 016/2000. A pesquisa foi aprovada pelo Comitê de Ética, sob o parecer n. $10711^{\mathrm{a}}$, bem como todos os participantes assinaram o Termo de Livre Esclarecido, onde são garantidos e esclarecidos todos seus direitos. Para efeitos éticos, os nomes dos participantes foram ocultados, tendo ao final de suas falas a sigla que os separa enquanto acadêmicos do primeiro período (EC) e acadêmicos formandos (EV).

\section{Análise e discussão dos resultados}

\section{“Para mim loucura é...": as representações sociais dos calouros de Psicologia}

As compreensões predominantes dos acadêmicos do primeiro período, acerca da loucura, assinalam diferentes perspectivas de interpretação para um mesmo fenômeno, conforme pode-se observar nas seguintes falas: 
“(...) eu entendo a loucura como uma falha sabe, um problema no fisiológico. $E u$ vejo loucura num sentido mais técnico, mais a questão genética, biológica sabe, alguma falha”. (EC4)

"É tomar uma atitude que não condiz com o que a sociedade espera que você tome, pois daí a sociedade já te vê como um louco, pois não é o que eles esperam que você faça. Então não é bem uma loucura, mas sim como a sociedade vê". (EC2)

"Eu acho que loucura (...) tem a ver com uma pessoa que tem uma facilidade em compreender as coisas de uma outra forma, só que a forma que ela compreenda seja difícil que os outros entendam, né?". (EC1)

Ao que se verifica, os conteúdos já apresentam esforço para uma compreensão crítica, balizada pela linguagem científica, contudo, ainda evidencia-se opiniões e compreensões em conhecimentos e explicações do universo popular - ou seja, no senso comum. As representações da loucura, aqui interpretadas, são compreendidas como construções sociais do pensamento que se originam do senso comum, que, interativamente, são formadas na dinâmica das relações sociais historicamente circunscritas, num determinado tempo e em determinada cultura (Jodelet, 2001; Moscovici, 1978; Vala, 1996).

Um mesmo fenômeno pode ser compreendido de diferentes formas, como já dizia Arruda (2002), sendo, portanto, comunicado socialmente de formas diversas, a partir dos processos de comunicação e aquisição do conhecimento. Para tanto, Kyrillos Neto (2004) apresenta 3 modelos que comumente norteiam as práticas em saúde mental na atualidade: a) exclusivamente organicista; b) exclusivamente sociológico e c) o componente subjetivo; sendo que cada uma delas traz em seu cerne uma definição do sujeito "alienado".
Sob o viés orgânico, "a população alvo é definida a partir da demanda de medicação que cada transtorno estabelece por seus desarranjos químicos e genéticos" (Kyrillos Neto, 2004, pg. 78), priorizando a supressão dos sintomas através da medicalização. Já pelo modelo sociológico, a "população alvo" é analisada devido a exclusão social, enfocando exclusivamente o desamparo da sociedade, desconsiderando qualquer aspecto clínico da sintomatologia. Pelo modelo da subjetividade, o sujeito com sofrimento psíquico é observado a partir de suas singularidades, que esteja em dificuldade na relação com o outro.

Não se exclui os fenômenos sociais, que, através da cultura e demais manifestações sociais, atravessam a realidade de cada sujeito, considerando que a subjetividade é mediada socialmente. Este último modelo também não nega o uso de medicação, porém, não percebe as mudanças orgânicas como gênese da loucura.

Estas 3 dimensões são passíveis de identificação nas falas citadas anteriormente e, por sua vez, apresentam uma condução de reflexão demarcada pelos aspectos individuais vivenciados até o momento pelos participantes. De constructo social para problemas cerebrais, a loucura perpassa por diferentes caminhos, mas que desemboca em um denominador comum, segundo os relatos: uma manifestação de comportamentos que estão em desacordo com o que está socialmente estabelecido.

Existe, pois, ao considerar a loucura como "doença mental", uma perspectiva cartesiana deste fenômeno, conforme observam Cabral e Albuquerque (2015) em seu estudo sobre a percepção de saúde mental que possuem os Agentes Comunitários de Saúde. Para Randemark, Jorge e Queiroz (2004), a "doença mental" é assim compreendida pela perda da racionalidade do homem, sendo que a cura não é vista a partir da aceitação da condição do indivíduo, mas sim o retorno à normalidade, centrando-se na 
doença e não nas potencialidades presentes no sujeito.

Compreensão esta que pode ser exemplificada a partir de falas como as apresentadas a seguir:

“(...) quando eu disse que loucura é estar fora de si mas também pode ser, tipo, uma inteligência aflorada. Se você for pra parar pra pensar assim, um exemplo na música, o Raul Seixas, (...) todo mundo via ele como mendigo, como louco, e foi só a partir da morte dele que começaram a vê-lo como inteligente (...)”. (EC7)

"Que nem o cara do filme "7 pecados". O cara quer falar dos 7 pecados e começa a matar as pessoas que cometem esses pecados, e tipo, ele era um cara muito inteligente, mas ele coloca essa inteligência dele para fazer coisas loucas (...)". (EC12)

Pôde-se perceber que algumas das percepções e valores sobre a loucura apresentadas acima ancoram a loucura em aspectos oriundos do campo midiático (músicos, filmes, etc.). Uma vez considerando que o fenômeno das representações sociais é, concomitantemente, um produto e um processo (Valsiner, 2003), e que as representações sociais possuem a comunicação de massa como condição de possibilidade e determinação para sua difusão (Jodelet, 2001), as considerações acima exemplificam as construções dos acadêmicos sobre a loucura que passam a fazer parte de seu cotidiano e se naturalizam por meio da mídia, ganhando assim uma imagem real de um fenômeno psicológico. A partir da mídia, os participantes passam a retratar conteúdos objetivos e subjetivos de indivíduos com transtornos mentais e da sociedade em que este está inserido, servindo de elo de ligação entre o conhecimento científico e o saber cotidiano, formando assim suas RS.
Uma representação não é uma simples cópia fidedigna de algum objeto existente na realidade objetiva, mas uma construção coletiva, entendidas como mediações simbólicas, em que as estruturas de conhecimento do grupo recriam o objeto com base nas representações já existentes (Neto \& Avellar, 2016). Isto permite aos participantes conceber e interpretar aspectos da realidade no caso, o fenômeno da loucura - e agir em relação à ela, haja vista que a representação toma o lugar do objeto social a que se refere e transforma-se na realidade, para os indivíduos envolvidos (Wachelke \& Camargo, 2005).

\section{"Um pouquinho é Transtorno Mental... o resto é social": A ciência reitificando as Representações dos formandos em Psicologia}

As representações sociais dos acadêmicos de Psicologia concluintes, por sua vez, permeiam outras formas de compreensão da loucura, como pode-se observar nas seguintes falas:

"Vejo que o mundo moderno traz muito esta questão do diferente. O diferente hoje não é mais visto como errado, mas também como autoafirmação. Alguns podem achar louco, mas outros também podem imitar. Claro que tem a questão de transtornos mentais, como a esquizofrenia e outras manifestações psicóticas, mas acredito que também esteja ligado a padrões sociais". (EV7)

"É que tudo aquilo que é desconhecido, a meu ver, pela maioria das pessoas, é taxado como louco, porque foge de sua realidade, foge do contexto na qual estão habituadas, e como não compreendem, acabam rotulando como loucura, sem ter o devido conhecimento sobre aquilo". (EV4) 
Denota-se aqui que, mesmo em posse dos conhecimentos acumulados ao longo dos cinco anos de sua formação, as falas ainda apresentam apontamentos fundados em premissas culturais. Reitera-se aqui que as representações sociais existem não apenas através de teorias científicas, mas também de grandes constructos culturais, ideológicos, bem como das experiências e da comunicação do cotidiano, onde indivíduos, em interação social, constroem suas teorias sobre objetos sociais (Moscovici, 1978; Vala, 1996).

Verifica-se a presença da dimensão científica do fenômeno da loucura. Para os acadêmicos concluintes, a loucura também é associada ao fenômeno dos transtornos mentais, ancorando-se nas imagens de doenças mentais graves, como a esquizofrenia e a noção de psicose. Logo, tais doenças mentais graves passam a ter o peso simbólico da loucura, na atualidade (Tenório, 2016).

O tempo de formação acadêmica passa a aparecer quando, junto destas falas, surgem também posicionamentos que denotam uma representação social reitificada na ciência. Nas exemplificações a seguir, denotamos reflexões que buscam a compreensão do fenômeno por meio de argumentos via análise semântica ou do campo da psicopatologia.

"Eu vejo a loucura, inicialmente num sentido semântico (...) a palavra loucura em si já tem um viés pejorativo, ou seja, alguém que se comportou de forma diferente ao que é normativo". (EV18)

\section{“(...) loucura para mim é vista como os transtornos mentais graves, bem como as conseqüências que estas atitudes podem trazer a ela, a exclusão e o julgamento moral que é imposto, por apresentar determinados sintomas". (EV6)}

O termo loucura, por si só, já traz em seu cerne uma conotação repleta de significação. Pode-se compreender a loucura - neste aspecto - como característica da alteridade, ou seja, o sujeito louco enquanto alguém imprevisível, que não está adequado às normas sociais, como se corrobora nas falas a seguir:

“(..) vejo a loucura mais voltada à
normais sociais, e a sociedade, com
seus padrões, julga se aquilo é
benéfico ou não, dentro de toda uma
organização política, econômica,
social, podendo ir de encontro à
condutas individuais". (EV14)

"O que existe é uma realidade com padrões nas quais tentamos nos adaptar, mas entre as quatro paredes da subjetividade humana, existem tantas coisas que poderiam nos impressionar!". (EV23)

“(...) seriam atitudes, comportamentos, que fogem à normalidade (...), pois algumas atitudes fogem aos padrões estabelecidos como normalidade". (EV19)

Uma questão importante provém da coerência nos discursos dos acadêmicos veteranos sobre a loucura, uma vez que estes, com todo o conhecimento acumulado ao longo de sua formação, analisam a loucura com mais propriedade como uma condição que também apresenta aspectos sociais e históricos. A leitura feita pelos participantes concluintes não remetem à loucura apenas ao transtorno, mas à fenômenos psicossociais, o que permite uma compreensão mais abrangente do fenômeno, não apenas enquanto manifestação de um transtorno, mas enquanto condição humana e expressão de sua subjetividade, construída também a partir de suas relações sociais (Tenório, 2016). Neste aspecto, Moscovici (1978) discorre que as características específicas de cada grupo social contribuem para as especificidades das representações.

Faz-se aqui uma demarcação importante sobre a representação social e sua 
interface com o fenômeno da loucura: seu aspecto contemporâneo. A loucura, mesmo com sua historicidade milenar, foi alterando seus modos de compreensão (Foucault, 1991), e é justamente por tal situação que a teoria das representações sociais emerge como meio para compreender tal fenômeno. Acerca disso, Moscovici (1984) discorre:

As representações sociais de que me ocupo não são as das sociedades primitivas (...). São as da nossa sociedade atual, do nosso solo político, científico e humano, e que nem sempre tiveram o tempo suficiente para permitir a sedimentação que as teorias tradicionais imutáveis (p. 181).

Contudo, diante das falas aqui apontadas, que permearam fundamentalmente dois sistemas representacionais (ciência e cultura) ambos não foram capazes de explicar suficientemente o que é loucura. Logo, o fenômeno da loucura enquanto objeto de pesquisa científica, ainda não consegue suficientemente explicar e alterar as teorias leigas acerca da loucura, uma vez que não foi capaz de trazer explicações para familiarizar este fenômeno, como já apresenta Wachelke (2005).

\section{Amarrando as falas: Que é loucura, afinal?}

Os acadêmicos - tanto iniciantes quanto concluintes - buscaram categorizar o fenômeno apresentado, mediante verbalizações que dessem sentido às suas explicações, intitulando a loucura sob diversas roupagens (loucura social, loucura mental, etc.). Segundo Moscovici (1984) as representações sociais, em suas funções, permitem que sentidos sejam criados dentro de sistemas de categorização, ou seja, classificar determinado sujeito como louco, neurótico ou excluído vai além de ratificar um valor, mas sim atribui a este indivíduo uma posição num sistema de categorias que advém das representações sobre doença mental (Vala,
1996), sociedade ou demais constructos que agregam valor ao fenômeno da loucura.

Para tanto, faz-se válido mencionar o estudo realizado por De Rosa, Bocci e Pedreira (2012) acerca das representações sociais e práticas do louco e da loucura para profissionais em saúde mental (incluindo psicólogos e estudantes de psicologia) e não especialistas. Este apresentou uma relação difusa entre representações e intenções comportamentais, com conteúdos estereotipados e de discriminação, embora também apresente discursos voltados a práticas de tolerância anti-estigma.

Ademais, observou-se nos resultados deste estudo a coexistência entre representações do louco e da loucura tanto antigas quanto modernas, científicas e leigas, o que é teoricamente conceituado como "polifasia cognitiva" (Moscovici, 1978, Nascimento \& Roazzi, 2008), isto é, a presença simultânea de modalidades diferentes de saber coexistindo em um mesmo indivíduo, grupo social ou comunidade. Característica essa passível de observação no presente estudo, contudo, que ainda denotam uma necessidade de maior profundidade intelectual, haja vista que não há como delatar uma compreensão fundamental do fenômeno.

Outra marcação importante aponta para a condição de loucura como um ícone da diferença, tal como é passível de observação em outros estudos, como de Moreira, Cavalcanti e Souza (2016), ao estudar os sentidos da deficiência a partir do habitus militar. Além disso, representar a loucura por meio de expressões comportamentais e atitudes que destoam do que é dado como padrão, também podem denotar uma dada intelectualidade ou expressão de arte, fato esse que, conforme a discussão de Franceschini e Fonseca (2017), contribui para o ajustamento daquilo que se contradiz com o que já está socialmente estabelecido. 


\section{Considerações finais}

Mediante os diálogos realizados nos grupos focais com os acadêmicos - tanto ingressantes quanto concluintes, evidenciaram-se noções diversas acerca do que é propriamente loucura, ora focando conteúdos que advém do próprio campo da psicopatologia, ora enfocando manifestações comportamentais de quebra das normas sociais. Na comparação dos discursos dos dois grupos observou-se que os iniciantes apontam concepções carregadas de experiências individuais, tencionando a um baixo consenso entre os membros, em detrimento dos concluintes que apresentam reflexões com conteúdos mais parecidos, sinalizando os rumos de sua formação acadêmica.

A loucura, para os acadêmicos ingressantes, é interpretada a partir de um crivo de análise oriundo dos meios de comunicação, haja vista que para embasar seus valores e crenças traziam casos noticiados na imprensa, bem como personalidades do rock e filmes, o que acaba por indicar onde se ancoram suas representações. Esta questão, por sua vez, indica a maneira como o assunto vem sendo abordado por tais mecanismos midiático são denotar-se que o olhar predominante dos iniciantes incorpora compreensões tangentes ao não funcionamento correto do organismo (mais particularmente do cérebro, de acordo com os discursos).

Em contraste a este quadro, os acadêmicos concluintes utilizam-se de linguagem acadêmica para balizar suas conceituações sobre a loucura, apontando dois pólos representacionais distintos: o campo psicopatológico e o campo social, como produtores e/ou mantenedores da loucura.Assim, reconhece-se a condução da formação e o impacto desta no campo representacional dos participantes, bem como sinaliza o modo como estes futuros profissionais irão operar diante desta questão.

Contudo, por ser um tema polêmico, é possível que exista uma zona muda das representações sociais da loucura, sendo necessários estudos mais amplos para verificar tal possibilidade. Para tanto, um dos fatores que merecem ser apontados neste estudo é a necessidade de espaço dentro do campo acadêmico para estudar propriamente a loucura. O campo da Psicologia e da Psiquiatria, mesmo com seus avanços científicos, ainda não domina com propriedade o campo da loucura, estabelecendo assim uma situação em que nem a ciência nem o campo cultural explicam precisamente o fenômeno aqui estudado.

Faz-se necessário abrir espaço para novos debates sobre o tema, visando familiarizá-lo não apenas no meio científico, mas ao campo laico. Propõe-se aqui a realização de novos estudos sobre o tema, visando aumentar a amostra populacional, proporcionando assim maiores dados que sustentem a importância do conhecimento das representações sociais da loucura e sua relação com as práticas voltadas ao fenômeno da loucura, nos diversos âmbitos da sociedade.

\section{Referências}

Alves, S. (1982). Do outro lado do Muro: estudo sobre representação social de doença mental em uma população favelada do Rio de Janeiro. Rio de Janeiro: Instituto de Psiquiatria da UFRJ.

Arruda, A. (2002) Teoria das representações sociais e teorias de gênero. Cadernos de Pesquisa, 117, 127-147.

Cabral, T. M. N., \& Albuquerque, P.C. de. (2015). Saúde mental sob a ótica de Agentes Comunitários de Saúde: a percepção de quem cuida. Saúde em Debate, 39(104), 159-171.

Caldas, D. L., \& Sá, C. P.(2004). A representação social de doente mental entre familiares de pacientes de dois modelos distintos de assistência à saúde mental. In: L. F. R. Tura, \& A. S. P. Moreira (Org.), Saúde e representações Sociais (pp. 55-70). João Pessoa: Editora Universitária.

Colvero, L. De A., Ide, C. A. C., \& Rolim, M. A. (2004). Família e doença mental: a 
difícil convivência com a diferença. Revista escolar de enfermagem da USP, 38(2), 197-205.

Conselho Federal De Psicologia. (201). Ementa: Dispõe sobre a realização de pesquisa em Psicologia com seres humanos. Recuperado de http://www.serdigital.com.br/gerenciador/cl ientes/crp/arquivos/66.pdf.

Conselho Nacional de Saúde. Diretrizes e Normas Regulamentadoras de Pesquisas Envolvendo Seres Humanos. (1996). Recuperado de http://www.sbpqo.org.br/suplementos/33\% 20-\%20Diretrizes.pdf.

Cunha, C. C., \& Boarini, M. L. (2016). A medicina com o voto de minerva: o louco infrator. Psicologia \& Sociedade, 28(3), 442-452.

De Rosa, A. (1987). The social representations of mental illness in children and adults. In:W. Doise, \& S. Moscovici Eds), Current issues in european social psychology (pp.47-138). Cambridge: Cambridge University Press.

De Rosa, A.; Bocci, E., \& Pedreira, T. (2012). Desapareceram os estigmas? Práticas e representações sociais do "louco" e da "loucura" entre especialistas brasileiros e especialistas em formação em um contexto de mudanças institucionais no Brasil. Revista Tempus Actas de Saúde Coletiva, 6(3), 161-186.

Fontanella, J. B., \& Magdaleno Júnior, R. (2012). Saturação teórica em pesquisas qualitativas: Contribuições psicanalíticas. Psicologia em Estudo, 17(1), 63-71.

Foucault, M. (1999). A história da loucura na idade clássica (6 ${ }^{\mathrm{a}}$. Ed). São Paulo: Perspectiva, 1999.

Franceschini, E., Fonseca, T. M. G. (2017). Arte e loucura como limiar para outra história. Psicologia USP, 28(1), 14-22.

Gaskell, G. \& Bauer, M. W. (2008). Para uma prestação de contas pública: além da amostra, da fidedignidade e da validade. In: G. Gaskell \& M. W. Bauer (Orgs), Pesquisa Qualitativa com texto, imagem e som: um manual prático $\left(7^{\mathrm{a}} \mathrm{ed}\right.$., pp. 470-490). Petrópolis, RJ: Vozes.
Gil, R. (2008). Análise de discurso. In: M. W. Bauer \& G. Gaskell (Orgs.), Pesquisa Qualitativa com texto, imagem e som: um manual prático ( $7^{\mathrm{a}}$ ed., pp. 244-270). Petrópolis, RJ: Vozes.

Jodelet, D. (1989). Folies et réprésentations sociales. Paris: Presses Universitaries de France.

Jodelet, D. (2005). Loucuras e representações sociais. Petrópolis, RJ: Vozes.

Jodelet, D. (2011). Representações sociais: um domínio em expansão. In: D. Jodelet (Org.), As representações sociais (pp. 1744). Rio de Janeiro: UERJ.

Krause, M. (2002). Social representations of psychological problems: contents and transformations. Social Science Information, 41, 603-623.

Kyrillos Neto, F. (2004). Basaglia em desuso? Ou notas sobre a importância de dialogar com Basaglia e basaglianos. Interacões, 9(18), 75-86.

Leme, M. A. V. DA S., Bussab, V. S. R., \& Otta, E. (1989). A representação social da Psicologia e do psicólogo. Psicologia ciência e profissão, 9(1), 29-35.

Machado, A. L. (2001). Espaços de representação da loucura: religião e psiquiatria. Campinas, SP: Papirus.

Marconi, M. de A., \& Lakatos, E. M. (2007). Fundamentos de metodologia científica (6. Ed.) São Paulo: Atlas.

Minozzo, F., Kammzetser, C. S., Debastiani, C., Fait, C. S., \& Paulon, S. M. (2012). Grupos de saúde mental na atenção primária à saúde. Fractal: Revista de Psicologia, 24(2), 323-340.

Morant, N., \& Rose, D. (2002). Loucura, multiplicidade e alteridade. In: A. Arruda (Org.), Representando a alteridade (pp.129-148). Petrópolis, Vozes.

Moreira, N. X., Cavalcanti, L. F., Souza, R. de O. (2016). Os sentidos atribuídos ao fenômeno da deficiência a partir do habitus militar. Ciência e saúde coletiva, 21(10), 3027-3035.

Moscovici, S. (1978). A representação social da psicanálise. Rio de Janeiro: Zahar. 
Moscovici, S. (1981). On social representations. In: J. P. Forgas, Social Cognition. London: Academic Press.

Moscovici, S. (1984). The phenomenon of social representations. In: R. Farr, \& S. Moscovici (Orgs.), Social Representations (pp.3-70). Cambridge: Cambridge University Press.

Moscovici, S. (2003). Representações sociais: investigações em Psicologia Social. Petrópolis, RJ: Vozes.

Moscovici, S., \& Hewstone, M. (1986). De la ciencia al sentido común. In: $\mathrm{S}$. Moscovici (Org.), Pensamiento y vida social (pp. 674710). Barcelona/Buenos Aires/México: Paidós.

Nascimento, A. M. Do, \& Roazzi A. (2008). Polifasia cognitiva e a estrutura icônica da representação social da morte. Psicologia: Reflexão e Crítica, 21(3), 499-508.

Neto, P. M. R. \& Avellar, L. Z. Concepções sobre a interação com moradores de Residências Terapêuticas. Psicol. Soc. 28(1), 162-170.

Pélicier, Y. (1971). História da Psiquiatria. Lisboa: Europa-América.

Perrusi, A. (1995). Imagens da loucura. São Paulo: Cortez editora.

Pessotti, I. (1994). A loucura e suas épocas. Rio de Janeiro: Ed. 34.

Randemark, N. F. R., Jorge, M. S. B., \& Queiroz, M. V. O. (2004). A reforma psiquiátrica no olhar das famílias. Texto e Contexto Enfermagem, 13(4), 543-550. Richardson, R. J. (2009). Pesquisa social: Métodos e técnicas. São Paulo: Atlas.

Roso, A. (1997).Grupos focais em Psicologia Social: da teoria à prática. Psico, 28(2), 155-169.

Rouquette, M. L. (1998). Representações e práticas sociais. In: A. S. P. Moreira, \& D. C. Oliveira (Orgs.), Estudos interdisciplinares de representação social (pp.39-46). Goiânia: AB.

Silva, J. de D. G. da, Aciole, G. G., \& Lancman, S. (2017). Ambivalências no cuidado em saúde mental: a 'loucura' do trabalho e a saúde dos trabalhadores. Um estudo de caso da clínica do trabalho. Interface - Comunicação, Saúde, Educação, 3, s/p.

Silva, M. S., \& Zanello, V. M. (2010).

Religiosidade e loucura: a influência da religião na forma como "doente mental" enfrenta a doença. Psicologia IESB, 2(1), 37-47.

Tenório, F. (2016). Psicose e esquizofrenia: efeitos das mudanças nas classificações psiquiátricas sobre a abordagem clínica e teórica das doenças mentais. História, Ciências, Saúde-Manguinhos, 23(4), 941963.

Vasconcelos, E. M. (2002). Complexidade e pesquisa interdisciplinar: epistemologia $\mathrm{e}$ metodologia operativa. (2 $2^{\mathrm{a}}$ ed.) Petrópolis: Vozes.

Vala, J. (1996). Representações sociais: para uma Psicologia Social do pensamento social. In: J. Vala, \&M. B. Monteiro, Psicologia Social (2a ed.) (pp. 569-602). Lisboa: Calouste Gulbekian.

Valsiner, J. (2003). Beyond social representations: a theory of enablement. Papers on Social Representations, 12(7), 17.

Wachelke, J. F. R.(2005). O vácuo no contexto das representações sociais: uma hipótese explicativa para a representação social da loucura. Estudos de Psicologia, 10(2), 313320.

Wachelke, J. F. R., \& Camargo, B. V. (2007). Representações sociais, representações individuais e comportamento. Revista Interamericana de Psicologia, 41(2), 379390.

Wagner, W., Duveen, G., Themel, M., \& Verma, J. (1999). The modernization of tradition: thinking about madness in Patna, India. Culture and Psychology, 5(4), 413445.

Dados sobre os autores:

- Adriano Schlosser é doutorando em Psicologia pelo Programa de Pós Graduação da Universidade Federal de Santa Catarina, área de concentração: saúde e desenvolvimento psicológico, Linha de 
pesquisa: Cognição e representações sociais (corpo, saúde e beleza). Psicólogo formado pela Universidade do Vale do Itajaí. Mestre em Psicologia - UFSC (2014). Membro do Laboratório de Psicologia Social da Comunicação e Cognição - LACCOS.

- Gabriel Fernandes Camargo Rosa é Mestre em Psicologia pelo Programa de Pós Graduação da Universidade Federal de Santa Catarina. Especialista em Saúde da Família UNIVALI. Docente do Centro Universitário de Brusque (UNIFEBE). 